\title{
Erratum: Tumor suppressor BRCA1 epigenetically controls oncogenic microRNA-155
}

Suhwan Chang, Rui-Hong Wang, Keiko Akagi, Kyung-Ae Kim, Betty K Martin, Luca Cavallone, Kathleen Cuningham Foundation Consortium for Research into Familial Breast Cancer (kConFab), Diana C Haines, Mark Basik, Phuong Mai, Elizabeth Poggi, Claudine Isaacs, Lai M Looi, Kein S Mun, Mark H Greene, Stephen W Byers, Soo H Teo, Chu-Xia Deng \& Shyam K Sharan Nat. Med. 17, 1275-1282 (2011); published online 25 September 2011; corrected after print 7 November 2011

In the version of this article initially published, Shyam K Sharan's affiliation was erroneously listed as affiliation 7, when it should have been affiliation 1. The error has been corrected for the PDF and HTML versions of this article.

\section{Erratum: Epidermal growth factor receptor promotes glomerular injury and renal failure in rapidly progressive crescentic glomerulonephritis}

Guillaume Bollée, Martin Flamant, Sandra Schordan, Cécile Fligny, Elisabeth Rumpel, Marine Milon, Eric Schordan, Nathalie Sabaa, Sophie Vandermeersch, Ariane Galaup, Anita Rodenas, Ibrahim Casal, Susan W Sunnarborg, David J Salant, Jeffrey B Kopp, David W Threadgill, Susan E Quaggin, Jean-Claude Dussaule, Stéphane Germain, Laurent Mesnard, Karlhans Endlich, Claude Boucheix, Xavier Belenfant, Patrice Callard, Nicole Endlich \& Pierre-Louis Tharaux Nat. Med. 17, 1242-1250 (2011); published online 25 September 2011; corrected after print 7 November 2011

In the version of this article initially published, the affiliations of the author Nathalie Sabaa were misidentified as affiliations 3 and 4 . Her correct affiliations are 6 and 7. The error has been corrected in the HTML and PDF versions of the article.

\section{Corrigendum: Dcx reexpression reduces subcortical band heterotopia and seizure threshold in an animal model of neuronal migration disorder}

Jean-Bernard Manent, Yu Wang, YoonJeung Chang, Murugan Paramasivam \& Joseph J LoTurco

Nat. Med. 15, 84-90 (2009); published online 21 December 2008; corrected after print 7 November 2011

In the version of this article initially published, the labels in the key to the bar graph in Figure $2 \mathrm{c}$ were incorrect. The gray bars should have been labeled 'Double cortex', and the white bars should have been 'P0 rescue'. The error has been corrected in the HTML and PDF versions of the article.

Corrigendum: Resolving controversies on the path to Alzheimer's therapeutics

Dennis J Selkoe

Nat. Med. 17, 1060-1065 (2011); published online 7 September 2011; corrected after print 21 October 2011

In the version of this article initially published, the name of the antibody bapineuzumab was incorrectly spelled as 'bapineuzimab' throughout the text. The error has been corrected in the HTML and PDF versions of the article. 